Published in final edited form as:

Behav Genet. 2015 March ; 45(2): 157-170. doi:10.1007/s10519-014-9704-4.

\title{
Genetic and Environmental Contributions to the Relationships between Brain Structure and Average Lifetime Cigarette Use
}

\author{
Elizabeth Prom-Wormley ${ }^{1,2}$, Hermine H.M. Maes ${ }^{1,3}$, J. Eric Schmitt ${ }^{1,14}$, Matthew S. \\ Panizzon ${ }^{4,5}$, Hong Xian ${ }^{6,7}$, Lisa T. Eyler ${ }^{4,11}$, Carol E. Franz ${ }^{4,5}$, Michael J. Lyons ${ }^{8}$, Ming T. \\ Tsuang $^{2,9}$, Anders M. Dale ${ }^{9,12}$, Christine Fennema-Notestine ${ }^{4,9}$, William S. Kremen ${ }^{4,5,10}$, \\ and Michael C. Neale ${ }^{1,13}$ \\ 1 Virginia Institute for Psychiatric and Behavioral Genetics, Virginia Commonwealth University \\ School of Medicine, Richmond, VA, USA \\ 2 Division of Epidemiology, Department of Family Medicine and Population Health, Virginia \\ Commonwealth University, Richmond, VA, USA \\ ${ }^{3}$ Department of Human and Molecular Genetics, Virginia Commonwealth University \\ ${ }^{4}$ Department of Psychiatry, University of California, San Diego, La Jolla CA, USA \\ ${ }^{5}$ Center for Behavioral Genomics Twin Research Laboratory, University of California, San Diego, \\ La Jolla, USA \\ ${ }^{6}$ Department of Statistics, St. Louis University, St. Louis, MO, USA \\ ${ }^{7}$ Research Service, VA St. Louis Healthcare System, St. Louis, MO, USA \\ 8 Department of Psychology, Boston University, Boston, MA, USA \\ 9 Department of Radiology, University of California, San Diego, La Jolla, CA, USA \\ ${ }^{10}$ Center of Excellence for Stress and Mental Health, VA San Diego Healthcare System, La Jolla, \\ CA, USA \\ ${ }^{11}$ Mental IIIness Research Education and Clinical Center, VA San Diego Healthcare System, San \\ Diego, CA, USA \\ 12 Department of Neurosciences, University of California, San Diego, La Jolla, CA, USA \\ 13 Department of Psychiatry, Virginia Commonwealth University \\ 14 Department of Radiology, University of Pennsylvania
}

\section{Abstract}

Chronic cigarette use has been consistently associated with differences in the neuroanatomy of smokers relative to nonsmokers in case-control studies. However, the etiology underlying the relationships between brain structure and cigarette use is unclear. A community-based sample of male twin pairs ages 51-59 (110 monozygotic pairs, 92 dizygotic pairs) was used to determine the

Correspondence should be directed to Dr. Elizabeth Prom-Wormley; Division of Epidemiology, Department of Family Medicine and Population Health, Virginia Commonwealth University, PO Box 980212, Richmond, VA 23298-0212; ecpromwormle@ vcu.edu. 
extent to which there are common genetic and environmental influences between brain structure and average lifetime cigarette use.

Brain structure was measured by high-resolution structural magnetic resonance imaging, from which subcortical volume and cortical volume, thickness and surface area were derived. Bivariate genetic models were fitted between these measures and average lifetime cigarette use measured as cigarette pack-years.

Widespread, negative phenotypic correlations were detected between cigarette pack-years and several cortical as well as subcortical structures. Shared genetic and unique environmental factors contributed to the phenotypic correlations shared between cigarette pack-years and subcortical volume as well as cortical volume and surface area. Brain structures involved in many of the correlations were previously reported to play a role in specific aspects of networks of smokingrelated behaviors. These results provide evidence for conducting future research on the etiology of smoking-related behaviors using measures of brain morphology.

\section{Keywords}

neuroimaging; twin study; smoking; adults; brain structure

\section{Background}

Despite increasing public awareness of the health risks related to smoking, nearly $18 \%$ of American adults were current cigarette smokers in 2012 (Agaku et al. 2014). Further, although $52.4 \%$ of smokers tried to quit, the prevalence of recent cessation for more than 6 months was only $6.2 \%$ (Centers for Disease and Prevention 2011). It is likely that morphological changes in the brain are related to chronic exposure to nicotine, which is the addictive component of cigarettes. The joint analysis of structural magnetic resonance imaging (MRI) measures of the brain and average lifetime use to nicotine may identify locations for more specific studies of the neurobiology of nicotine dependence. Further, the degree to which shared genetic and environmental contributions explain these associations is unclear and could provide additional knowledge in assessing the utility of neuroanatomy as a possible biological marker for understanding the etiology of chronic cigarette use.

\section{Associations between Cigarette Use and Brain Structure}

Cigarette use has been associated with size reductions across several brain structures.

Reduced cell numbers, increased markers of apoptosis and alterations in synaptic activity in the neocortex, hippocampus, midbrain and cerebellum have been observed in adult rats exposed to nicotine (Chen et al. 2003; Trauth et al. 2000; Trauth et al. 1999; Xu et al. 2001). A case-control study comparing smokers to non-smokers reported smaller volumes in the prefrontal and anterior cingulate cortices as well lower gray matter density in the cerebellum of smokers (Brody et al. 2004). Smokers had reduced gray matter volumes or densities in portions of frontal lobe subregions, occipital cortex, cuneus, precuneus, and the thalamus compared to never-smokers. Smokers were also found to have a negative correlation between frontal lobe gray matter volume and cigarette pack-years (Gallinat et al. 2006). 
Studies of nicotine dependence have implicated specific brain regions, particularly the orbitofrontal cortex, prefrontal cortex, cingulate gyrus, anterior cingulate, nucleus accumbens, thalamus, and frontal cortex (Goldstein and Volkow 2002; Rose et al. 2007). However, the biological mechanisms related to chronic exposure to cigarettes remains unclear (Menossi et al. 2013). Therefore, understanding the role of genetic and environmental influences shared between brain neuroanatomy and smoking may provide insight into processes involved in smoking-related behaviors.

\section{Twin Studies of Smoking-Related Behaviors}

Significant genetic influences have been reported across stages of nicotine selfadministration including initiation, smoking persistence, nicotine dependence, and nicotine withdrawal. Additive genetic effects account for 30-75\% of the total variance of nicotine dependence across several studies (Agrawal et al. 2008; Pergadia et al. 2006). Similarly, a meta-analysis of 17 twin studies estimated a weighted mean heritability of liability for smoking persistence of 59\% in male smokers and 46\% female smokers (Li et al. 2003). Few twin studies have reported measures of average lifetime cigarette use, often measured as pack-years, although this measure has been used more consistently in the structural imaging studies (Gallinat et al. 2006). Subsequently, there is a need to assess the genetic contributions of average lifetime cigarette use as an important smoking-related behavior to determine its relationship with brain structure in a twin sample.

\section{Twin Studies of Brain Structure}

The genetic contribution to the variance in the size of brain regions for typical neurodevelopment across the lifespan is high (for review, see (Kremen et al. 2010; Peper et al. 2007; Schmitt et al. 2007; Blokland et al. 2012)). Among these studies, heritability values for regional structures were generally more variable and lower than global indices. In adults, additive genetic influences accounted for $40-75 \%$ of the total variance for different neuroanatomical measures. In general, there are few regions that have evidence of significant shared environmental effects (Peper et al. 2007; Schmitt et al. 2007; Baare et al. 2001; Geschwind et al. 2002; Glahn et al. 2007; Thompson et al. 2001), although lateral ventricular volume during childhood and adolescence may be an exception (Kremen et al. 2012).

Despite reports of moderate phenotypic association between nicotine use and brain volume (Chen et al. 2006; Longstreth et al. 2000; Seshadri et al. 2004), our understanding of the extent to which any significant relationships are due to common genetic or environmental effects is limited. Cortical volume, a well-studied measure, is the product of cortical thickness and surface area. But, cortical surface area and cortical thickness quantify different aspects of structural development over the lifespan. Studies of inter-individual variation in adult brain size indicate that the majority of differences in cortical gray matter volume are due to differences in cortical surface area rather than cortical thickness (Pakkenberg and Gundersen 1997; Im et al. 2008). At the global level, there is no significant genetic covariance between surface area and thickness (Panizzon et al. 2009). Therefore, surface area and thickness are distinct features of cortical structure and should be examined separately in studies of associations between brain morphology and other phenotypes of 
interest. However, we are not aware of any studies that have investigated the relationship between nicotine use and these constituent dimensions.

The present study tests for significant phenotypic relationships between brain structure and average lifetime cigarette use in a community-based sample of adult male twins. Further, it estimates the degree to which shared genetic and environmental contributions are responsible for these associations between brain morphology and average lifetime cigarette use.

\section{Methods}

\section{Participants}

Data were obtained from participants in the Vietnam Era Twin Study of Aging (VETSA), a longitudinal study of cognition and aging of male twins (Kremen et al. 2013; Kremen et al. 2013; Kremen et al. 2006). All participants in the VETSA were drawn from the Vietnam Era Twin (VET) Registry, a nationally distributed sample of twin pairs who served in the United States military between 1965 and 1975 (Goldberg et al. 2002). Detailed descriptions of the VET Registry's composition and method of ascertainment have been previously reported (Eisen et al. 1987; Henderson et al. 1990). This community-based sample has been found to be representative of middle-aged males in the United States with respect to their distributions of socioeconomic and health characteristics. (Schoneneborn \& Heyman, 2009---KREMEN 2012).

The VETSA1 MRI study began in year three of the primary VETSA project and data was conducted from 2005 to 2007 . Upon initial contact, $6 \%$ of the sample declined to participate. Participants were excluded from the study for reasons such as metal in the body $(7 \%)$, claustrophobia (3\%), inability to travel to the testing site $(5 \%)$, problems with the scanner $(8 \%)$, the exclusion of their co-twin (9\%), or other reasons $(3 \%)$. Participants traveled to the University of California, San Diego Medical Center (UCSD) or Boston University for the VETSA project and were scanned the next day at UCSD or Massachusetts General Hospital (MGH). Informed consent was obtained from all participants and institutional review boards at both sites approved the scanning protocol. The present analyses were performed on data from 474 participants (110 monozygotic (MZ) pairs, 92 dizygotic (DZ) pairs, 68 unpaired individuals) ranging in age from 51 to 59 years (mean $=55.8, \mathrm{SD}=2.6$ ) for whom suitable imaging data were available. A combination of DNA testing, previously obtained questionnaire and blood group methods was used to determine zygosity (Kremen et al. 2010; Eisen et al. 1989; Nichols and Bilbro 1966; Peeters et al. 1998).

\section{Assessment of Cigarette Use}

Average lifetime cigarette use was assessed during the VETSA1 MRI study as cigarette pack-years, defined as average cigarette use over years of smoking. Pack-years was calculated for all participants as the number of cigarettes smoked per day multiplied by the number of years smoked. This product was divided by 20 , or the number of cigarettes in a single pack. Current smokers were asked the number of cigarettes they usually smoke per day. Participants who were former smokers were asked the number of cigarettes they usually 
smoked per day during the last time they were a regular smoker. Both current and former smokers were asked the age at which they began smoking. Former smokers were asked the age at which they stopped smoking to determine the number of years smoked. Age at the time of data collection was used to determine smoking duration among current smokers. Individuals who indicated having smoked fewer than 100 cigarettes in their lifetime were classified as having an average lifetime cigarette use of zero pack-years. The distribution of pack-year values was skewed, so the data were $\log 10$ transformed prior to data analysis to approximate a normal distribution. Pack-years was strongly associated with a prior measure of the number of lifetime nicotine dependence symptoms $(r=0.70, p<0.0001)$ among a sub-sample of individuals who participated in a study of drug dependence in 1992 (Xian et al. 2007).

\section{Image Acquisition}

Images were acquired on Siemens 1.5 Tesla scanners (241 at UCSD; 233 at MGH). Sagittal T1-weighted MPRAGE sequences were employed with a TI $=1000 \mathrm{~ms}, \mathrm{TE}=3.31 \mathrm{~ms}$, $\mathrm{TR}=2730 \mathrm{~ms}$, flip angle $=7$ degrees, slice thickness $=1.33 \mathrm{~mm}$, voxel size $1.3 \times 1.0 \times 1.3 \mathrm{~mm}$. Of the 493 scans available at the time of these analyses, quality control measures excluded 3 cases due to scanner artifact and 16 cases due to inadequate image processing results (e.g., poor contrast caused removal of non-brain to fail).

Image Processing - The automated, fully 3D whole-brain segmentation procedure(Fischl et al. 2002; Fischl et al. 2004) in FreeSurfer uses a probabilistic atlas and applies a Bayesian classification rule to assign a neuroanatomical label to each voxel. The atlas consists of a manually-derived training set created by the Center for Morphometric Analysis (http:// www.cma.mgh.harvard.edu/) from 20 unrelated, randomly selected VETSA participants. The accuracy of a previously used training atlas has been shown to be comparable to that of expert manual labeling and is sensitive to subtle brain changes in Alzheimer's disease and normal aging (Fischl et al. 2002; Fischl et al. 2004). Manual labeling for the VETSAspecific atlas and the previously used atlas was performed by the same laboratory at the Center for Morphometric Analysis. When both were compared with expert manual labeling, the VETSA- specific atlas was shown to be more accurate than the previously used training atlas in this sample (Kremen et al. 2010).

Volume Measures-Segmentation methods (Fischl et al. 2002; Fischl et al. 2004) produced volumetric measures for 33 bilateral cerebral gray matter regions of interest (ROIs) that are not included in the neocortical surface, including hippocampus, amygdala, caudate, putamen, nucleus accumbens, thalamus, globus pallidus, cerebellar gray and white matter, ventricles (body and temporal horn of the lateral ventricle, third ventricle), cerebral cortex, white matter, and abnormally hypointense white matter regions. Measured white matter abnormalities reflect areas within the white matter that have abnormally low signal values (hypointensities) relative to normal white matter on T1-weighted images. These areas are analogous to the measure of hyperintensity derived from T2-weighted images and may reflect areas of inflammation, demyelination, or axonal loss. 
Neocortical Surface Area and Thickness Measures-The cortical surface was reconstructed to measure surface area and thickness at each surface location, or vertex (Fischl et al. 2004; Dale et al. 1999; Fischl and Dale 2000; Fischl et al. 1999). Studies demonstrate a high correlation of automatic and manual measures in vivo and ex vivo (Fischl and Dale 2000; Walhovd et al. 2005).

The surface was then divided into distinct cortical ROIs (Fischl et al. 2004). Each vertex was assigned a neuroanatomical label based on 1) the probability of each label at each location in a surface-based atlas space, based on a manually parcellated training set; 2) local curvature information; and 3) contextual information, encoding spatial neighborhood relationships between labels (conditional probability distributions derived from the manual training set). The parcellation scheme (Desikan et al. 2006) labels cortical sulci and gyri, then surface area and thickness values are calculated in the 66 ROIs (33 per hemisphere). Cortical thickness was calculated as the average distance between the gray/white boundary and the pial surface within each ROI. Surface area was calculated as the sum of the areas of each tesselation falling within a given ROI; this is done in each subjects' native space.

\section{Statistical Analysis}

Univariate variance component analysis characterized the relative importance of genetic and environmental effects on pack-years. Univariate analyses for all brain measures have been reported extensively in prior studies and are detailed (Kremen et al. 2010; Eyler et al. 2011; Eyler et al. 2012). The degree of relatedness between members of MZ and DZ twin pairs is used to estimate the contribution of genetic and environmental effects to the phenotypic variation of nicotine use and brain structure. Phenotypic similarities between MZ twins arise from the sharing of all their additive genetic factors and all shared environmental influences. Similarities between DZ twins result from sharing on average 50\% of their additive genetic factors in addition to shared environmental influences. Influences from unique environmental effects diminish the similarity between members of a twin pair, regardless of their zygosity. Models using twin data thus utilize MZ and DZ twin pair variances and covariances to estimate the proportion of total phenotypic variance due to additive genetic, shared environmental and unique environmental influences.

Additive genetic variance (A) refers to the additive genetic effects of alleles at every contributing locus. Shared environmental variance $(C)$ is the variance that is due to effects shared by a twin pair. Unique environmental variance (E) is the variance due to effects not shared by a twin pair and also includes measurement error. The total variance of a measure $\left(\sigma^{2} \mathrm{P}\right)$ is partitioned into additive genetic $\left(\sigma_{\mathrm{A}}^{2}\right)$, non-shared or unique environmental effects $\left(\sigma^{2} \mathrm{E}\right)$, and shared environmental effects $\left(\sigma^{2} \mathrm{C}\right)$. The total variance is parameterized as: $\sigma^{2} \mathrm{P}=\sigma_{\mathrm{A}}^{2}+\sigma_{\mathrm{C}}+\sigma_{\mathrm{E}}^{2}$, while the covariance terms are parameterized as: $\operatorname{Cov}_{\mathrm{MZ}}=\sigma_{\mathrm{A}}^{2}+\sigma^{2} \mathrm{C}$ and $\operatorname{Cov}_{\mathrm{DZ}}=.5 \sigma^{2} \mathrm{~A}+\sigma^{2} \mathrm{C}$. Univariate $\mathrm{ACE}, \mathrm{AE}, \mathrm{CE}$ and $\mathrm{E}$ only models were fitted to test the significance of additive genetic and shared environmental effects.

Bivariate Analysis-A genetic bivariate model assessed the relationship between brain structure and number of cigarette pack-years, treating both measures as continuous variables. Shared environmental effects were non-significant in univariate analyses of brain 
structure (Kremen et al. 2010; Eyler et al. 2011; Eyler et al. 2012). Similarly, there were no significant differences between a full model and submodels for which shared environmental effects on brain structure as well as the shared environmental covariance shared between brain structure and cigarette pack-years were removed. Therefore, bivariate models decomposed the covariance between brain structure and cigarette pack-years into genetic and unique environmental variance while estimating the contribution of shared environmental influences for cigarette pack-years (Figure 1).

A Cholesky factorization allows for the decomposition of the genetic and environmental covariance matrices for measures of brain structure and cigarette pack-years. The diagonal elements of either an A or E matrix produces the variances due to that specific effect for each of the individual measures while the off-diagonal element produces the covariances due to either of the effects. Further, it places few expectations on the temporal ordering of the relationship between the two measures.

Genetic and environmental correlations between measures of brain structure and use were computed to estimate the degree to which genetic and environmental effects are shared between the two measures. Additionally, standardized genetic covariances $\left(\operatorname{cov}_{\mathrm{A}}\right)$ were also estimated to indicate the degree to which genetic and environmental effects contribute to the phenotypic correlation $\left(\mathrm{r}_{\mathrm{P}}\right)$. The sum of the standardized genetic and environmental covariances is equal to the phenotypic correlation. The standardized genetic covariance between two measures is defined as

$$
r_{x, y}=\frac{A_{x, y}}{\sqrt{\left(V_{x} \times V_{y}\right)}}
$$

where $A_{x y}$ is the genetic covariance between a measure of brain structure $(x)$ and a measure of cigarette pack-years ( $y$ ) and $V_{x}$ and $V_{y}$ represent the total covariances of $x$ and $y$. The standardized environmental covariance $\left(\operatorname{cov}_{\mathrm{E}}\right)$ is similarly defined using measures of unique environmental covariance.

Morphometric measures were adjusted for the fixed effects of age and site using linear regression. Further, structural measures were adjusted for global size. Volume measures were adjusted for estimated total intracranial volume, neocortical surface area measures for total surface area, and neocortical thickness measures for total average cortical thickness. The residual estimates were then used in full information maximum likelihood analyses of individual observations in Mx 1.66 (Neale et al. 2006).

The statistical significance of the genetic and environmental covariances was assessed by comparing twice the log-likelihood of the full Cholesky model to that of a sub-model in which the genetic or environmental covariation between morphometric measures and packyears was set to zero $(\mathrm{df}=1)$. Under certain regularity conditions, such differences are asymptotically distributed as chi-squared with one degree of freedom. A third sub-model tested the significance of the phenotypic correlation by setting both the genetic and unique environmental covariances between nicotine use and cortical volumes to zero $(\mathrm{df}=2)$. 
A series of bivariate models tested the significance of genetic and environmental covariances between smoking and cortical thickness as well as surface area using globallyadjusted measures of surface area as well as cortical thickness. These models estimated the degree to which region-specific genetic and environmental influences were also shared with cigarette pack-years.

Tests of significance for genetic and environmental covariances were adjusted for multiple comparisons using the false discovery rate, FDR (Benjamini and Hochberg, 1995) based on 388 independent tests for all subcortical and cortical measures.

\section{Results}

\section{Descriptive Statistics}

Basic demographic and health characteristics of the full VETSA sample are comparable to U.S. census data for similarly aged men (Kremen et al. 2006). The VETSA1 MRI subsample did not differ significantly from the full VETSA sample with respect to the above demographic measures, nor were there significant differences between MZ and DZ twins. There were no significant group differences for the mean number and variance of pack-years or brain morphometric measures between MZ and DZ twins.

VETSA1 MRI participants had significantly less average lifetime cigarette use (mean = 16.9 pack-years, $\mathrm{SD}=21.6$ ) compared to non-MRI participants (mean $=21.39$ pack-years, $\mathrm{SD}=$ 2.23, $\mathrm{p}=0.001)$. While MRI participants smoked fewer pack-years compared to nonparticipants, any bias is expected to attenuate rather than overstate the magnitude of effects reported in this study. Additionally, MRI participants were significantly older ( mean $=55.8$, $\mathrm{SD}=2.6$ years) than non-MRI participants (mean $=55.3, \mathrm{SD}=2.4$ years, $\mathrm{p}=0.0005$ ), but this very small difference is due to the later start of the VETSA1 MRI study compared to the VETSA sample and is unlikely to affect the results.

At the time of data collection, 300 participants (63\%) smoked 100 or more cigarettes in their lifetime. Of these participants, $247(82.3 \%)$ made at least one quit attempt in their lifetime and $112(37.3 \%)$ were current smokers. Across the VETSA1 MRI sample, study participants had an average lifetime cigarette exposure of 27.5 pack-years. Current smokers had significantly higher levels of lifetime cigarette exposure (35.9 pack-years) compared to nonsmokers (22.0 pack-years, $\mathrm{p}<0.0001)$. Across the VETSA1 MRI sample, study participants smoked an average 21.5 cigarettes per day $(\mathrm{SD}=13.5)$ during times of regular smoking. The average duration of smoking for this sample was 24.2 years $(\mathrm{SD}=14.0)$. There were no significant differences in total intracranial volume, total surface area or average cortical thickness by current smoking status.

\section{Univariate Analyses}

The intra-pair correlations for pack-years for MZ and DZ twins were 0.60 and 0.45 respectively. The amount of the total variance due to additive genetic effects was 0.29 (95\% $\mathrm{CI}=0$; 0.67). Shared environmental effects accounted for $0.31(95 \% \mathrm{CI}=0 ; 0.59)$ and unique environmental effects accounted for $0.40(95 \% \mathrm{CI}=0.31 ; 0.53)$ of the total variance. There were no significant differences in model fit between the full ACE model and models 
where either shared environmental effects $(p=0.46)$ or additive genetic effects $(p=0.55)$ were removed. However, there was a significant difference in model fit when both $\mathrm{A}$ and $\mathrm{C}$ were removed compared to the full ACE model, suggesting significant effects of both genetic and shared environmental sources of variance. The heritability of subcortical volumes ranged from $0.48-0.85$ and those of cortical volumes ranged from 0.03-0.79. The cortical surface area heritability estimates ranged from $0.20-0.60$ and those of cortical thickness were from 0.05-0.57 (Kremen et al. 2010; Eyler et al. 2011).

\section{Bivariate Analyses}

Associations between Subcortical Volume and Cigarette Pack-years-Moderate negative phenotypic correlations were observed between cigarette pack-years and three subcortical volumes. These associations indicate relationships between higher levels of cigarette pack-years and a reduction in volume for these specific structures. The significant phenotypic correlation between left cerebellum cortex and cigarette pack-years $\left(\mathrm{r}_{\mathrm{P}}=-0.11, \mathrm{p}\right.$ $=0.03)$ was largely due to genetic factors shared between the two $\left(\operatorname{cov}_{\mathrm{A}}=-0.13, \mathrm{p}=0.04\right)$ rather than shared unique environmental factors $\left(\operatorname{cov}_{\mathrm{E}}=0.02, \mathrm{p}=0.68\right)$. The genetic correlation between left cerebellum cortex and pack-years was $-0.28(95 \% \mathrm{CI}=-1 ;-0.02)$, indicating a moderate degree of genetic influences shared between the two. Further, these results suggest that genetic influences related to increased cigarette pack-years are expected to decrease volume in the left cerebellum cortex (Table I).

Significant phenotypic correlations between cigarette pack-years and measures of subcortical volume were due to significant sharing of unique environmental factors. These relationships were detected for left accumbens $\left(r_{P}=-0.03, p=0.01 ; \operatorname{cov}_{E}=-0.10, p=0.01\right)$ and left pallidum $\left(r_{P}=-0.07, p=0.03 ; \operatorname{cov}_{E}=-0.08, p=0.01\right)$. Unique environmental factors involved in higher levels of cigarette pack-years were also associated with decreased volumes for these regions, as indicated by the moderate environmental correlations between smoking and left accumbens $\left(\mathrm{r}_{\mathrm{E}}=0.24,95 \% \mathrm{CI}=-0.4 ;-0.05\right)$ as well as left pallidum $\left(\mathrm{r}_{\mathrm{E}}=\right.$ $-0.21,95 \% \mathrm{CI}=-0.38 ;-0.03)$.

\section{Associations between Cortical Thickness and Cigarette Pack-years-There} were significant phenotypic correlations between cigarette pack-years and two cortical thickness measures, specifically right lateral occipital gyrus $\left(r_{P}=-0.15,95 \% \mathrm{CI}=-0.25\right.$; $-0.04, p=0.03)$ and left paracentral gyrus $\left(r_{P}=-0.13,95 \% C I=-0.23 ;-0.02, p=0.02\right)$. These correlations were due to substantial genetic covariances (right lateral occipital $=$ $-0.13,95 \% \mathrm{CI}=-0.26 ;-0.01, \mathrm{p}=0.03$; left paracentral $=-0.12,95 \% \mathrm{CI}=-0.24 ; 0, \mathrm{p}=0.04$ ). The genetic correlations indicated some overlap between the genetic factors shared between cigarette pack-years and these ROIs $\left(\mathrm{r}_{\mathrm{A}}=-0.15\right.$ and -0.13$)$.

There were two weak phenotypic correlations between measures of cortical thickness and cigarette pack-years for two regions in the temporal lobe, specifically, the right transverse temporal gyrus $\left(\mathrm{r}_{\mathrm{P}}=-0.09, \mathrm{p}=0.001\right)$ and the right middle temporal gyrus $\left(\mathrm{r}_{\mathrm{P}}=0.05, \mathrm{p}=\right.$ 0.01). These correlations were due to significant unique environmental covariances (right transverse temporal gyrus $\left[\operatorname{cov}_{\mathrm{E}}=-0.12,95 \% \mathrm{CI}=-0.21 ;-0.04, \mathrm{p}=0.002\right]$ and right middle temporal gyrus $\left.\left[\operatorname{cov}_{\mathrm{E}}=0.11,95 \% \mathrm{CI}=0.03 ; 0.19, \mathrm{p}=0.01\right]\right)$. The unique environmental 
correlations were moderate in magnitude, indicating some overlap between the unique environmental factors shared between cigarette pack-years and these neocortical ROIs $\left(\mathrm{r}_{\mathrm{E}}=\right.$ -0.26 and 0.23$)$.

Associations between Cortical Surface Area and Cigarette Pack-years-Among surface area measures, there were significant standardized genetic covariances $\left(-0.17<\operatorname{cov}_{\mathrm{A}}\right.$ $<-0.13, \mathrm{p}=0.01-0.04)$ between pack-years and the frontal lobe and cingulate cortex ROIs, with significant negative phenotypic correlations $\left(-0.14<\mathrm{r}_{\mathrm{P}}<-0.08, \mathrm{p}=0.02-0.04\right)$. These regions include left rostral anterior cingulate, right caudal anterior cingulate, right pars opercularis, and left frontal pole (Table II). The magnitude of the genetic covariance was fairly consistent across adjusted and unadjusted measures of surface area. The average genetic covariance among unadjusted ROIs was -0.15 while those adjusted for total surface area was -0.13 (Table III).

Significant phenotypic correlations between surface area and cigarette pack-years $\left(-0.13<\mathrm{r}_{\mathrm{P}}\right.$ $<-0.11, \mathrm{p}=0.0001-0.02)$ explained by significant unique environmental factors $(-0.13<$ $\left.\operatorname{cov}_{\mathrm{E}}<-0.10, \mathrm{p}=0.005-0.04\right)$ were observed for three specific regions within the frontal lobe and cingulate cortex. These regions include the right rostral middle frontal, left posterior cingulate, and left pars orbitalis (Table II). The magnitude of the environmental covariance was fairly consistent across adjusted and unadjusted measures of surface area, although the relationship between the left pars orbitalis was no longer significant after adjustment for surface area (Table III). The average environmental covariance among unadjusted ROIs was -0.12 while those adjusted for total surface area was -0.13 .

Associations between Neocortical Volume and Cigarette Pack-years-There were widespread negative associations between cigarette pack-years and decreased neocortical volume adjusted for total intracranial volume (Figure 2). Of the 11 correlations that were significant, genetic covariances substantially contributed to associations in five specific cortical ROIs, which are located in the frontal, occipital, parietal, and cingulate lobes. The significant genetic influences shared between smoking and these ROIs $(-0.17<$ $\left.\operatorname{cov}_{\mathrm{A}}<-0.12 ; \mathrm{p}=0.01-0.05\right)$ contributed to the majority of the phenotypic correlations between cigarette pack-years and their respective volumetric measures $\left(-0.18<\mathrm{r}_{\mathrm{P}}<-0.11, \mathrm{p}\right.$ $=0.01-0.10)$ in the right pars opercularis, right lingual gyrus, right caudal anterior cingulate, and right precuneus. The magnitude of the genetic correlations indicate moderate overlap between the shared genetic factors which increase cigarette pack-years and decrease volume in these ROIs $\left(-0.40<\mathrm{r}_{\mathrm{A}}<-0.31\right.$; Table I).

Of the significant phenotypic correlations between cigarette pack-years and neocortical volume, five were detected in cingulate and temporal lobe regions including left pars orbitalis and bilateral rostral middle frontal regions of the frontal lobe, the left posterior cingulate, left middle temporal gyrus and right inferior temporal gyrus $\left(-0.14<\mathrm{r}_{\mathrm{P}}<-0.07\right.$, $\mathrm{p}$ $=0.0001-0.02)$. Unique environmental factors shared between cigarette pack-years and these ROIs substantially contributed to these correlations $\left(-0.14<\operatorname{cov}_{\mathrm{E}}<-0.07 ; \mathrm{p}=\right.$ 0.0002-0.01; Table I). The magnitude of the unique environmental correlations indicate moderate overlap between the shared environmental influences which increase cigarette 
pack-years and decrease volume in these ROIs $\left(-0.31<\mathrm{r}_{\mathrm{E}}<-0.21\right)$. After correction for multiple testing using FDR, these results were no longer significant.

\section{Discussion}

The goal of this exploratory study was to determine the role of shared genetic and environmental influences on the phenotypic correlations between brain structure and cigarette pack-years. This is one of the first studies to address the relationship of brain structure and chronic smoking. These results are expected to guide future genetic association studies in neuroimaging and smoking-related behaviors. Given the loss of all significant results after correction for multiple testing, cautious interpretation and additional replication in other populations is suggested. Nevertheless, significant results prior to FDR adjustment highlight several interesting features of the etiology of nicotine dependence that have been reported elsewhere in the nicotine dependence literature. We summarize and discuss these results below and identify areas for additional study.

We found significant associations between average lifetime cigarette use and neocortical surface area, thickness and volume as well as subcortical volume. Generally, there were negative correlations across the cortical and subcortical structures, indicating that higher levels of cigarette pack-years are associated with smaller size of brain structure measures.

Several aspects of the relationship between brain structure and average lifetime cigarette use are highlighted, specifically (1) small magnitude correlations between structural brain measures and cigarette pack-years are widespread in the brain, (2) additional evidence for pathways in the brain related to specific aspects of average lifetime cigarette use, and (3) the identification of neocortical surface area as a possible morphometric measure to aid in the understanding structural changes related to average lifetime cigarette use.

\section{Widespread Associations of Small Magnitude between Cigarette Pack-Years and Measures of Brain Structure}

Across all measures, smaller brain structures were associated with increasing cigarette packyears. However, the magnitudes of these correlations were moderate to small in magnitude. Similar results have been reported in prior studies using community-based samples (Chen et al. 2006; Das et al. 2012). Structural alterations are considered to be important for processing information in dynamic networks according to environmental demands. The occurrence of dynamic structural alterations has been demonstrated to mirror functional processing in order to address external demands placed on the brain and to do so relatively efficiently and consistently (May et al. 2007). Despite the neurotoxic properties of smoking (Ferrea and Winterer 2009), chronic exposure to nicotine induces neuroadaptation (Menossi et al. 2013) rather than severe dysfunction. Therefore, a measure of lifetime cigarette use, such as that captured in pack-years may be expected to have small phenotypic correlations with brain morphometry.

Significant correlations of pack-years and brain structure were due to both significant shared genetic and environmental influences shared between the two, indicating multiple pathways by which the brain processes the demands related to smoking. Therefore, different patterns 
of genetic and environmental influences between specific regions and pack-years are expected to highlight different networks in the brain related to smoking etiology.

\section{Genetic and Environmental Covariances for Volume and Surface Area Provide Additional Evidence for Pathways Related to Smoking}

In the absence of correlations between pack-years with neocortical surface area or thickness, it is possible that there could be correlations with volume. For example, this might suggest an interactive effect. Here, the neocortical regions with significant correlations between pack-years and volume tended to have significant surface area correlations (although not always on the same side). Further, given the relative consistency in results measured either as volume or surface area, it is important to note that any relationships identified between cortical volume measures and smoking are likely to be due to cortical surface area. These results are similar to prior studies where differences in cortical gray matter volume were driven almost exclusively by differences in surface area (Im et al. 2008; Pakkenberg and Gundersen 1997). Cortical surface area has been reported as an appropriate descriptor to study brain network organization (Sanabria-Diaz et al. 2010) and the significant relationships between surface area and pack-years may reflect networks related to smokingrelated behaviors. Prior data from animal, human and in vivo studies have identified four distinct neurological networks for smoking (O'Doherty et al. 2000; Breiter and Rosen 1999; Koob and Volkow 2010; Volkow et al. 2003). Therefore, the detection of associations between cigarette pack-years and surface area suggest the importance of studying networks of brain structures related to smoking-related behaviors.

Shared genetic factors contributed to significant phenotypic correlations between cigarette pack-years and cortical surface area and volume in the right caudal anterior cingulate cortex and right pars opercularis (prefrontal cortex) as well as subcortical volume in the left cerebellum cortex. These ROIs have been previously identified in a network related to the control of smoking behavior (O'Doherty et al. 2000; Breiter and Rosen 1999; Koob and Volkow 2010; Volkow et al. 2003). There are several genes were identified through prior genetic association studies that are also are likely to be expressed in these ROIs. For example, prior studies in humans report upregulation of nicotinic acetylcholine receptors (nAChRs) genes resulting from cigarette smoking in the prefrontal cortex, brainstem and cerebellum. Genes responsible for the nicotinic receptor subunits (CHRNA5, CHRNA3 and CHRNB4) alter receptor activity and sensitivity to nicotine. Variants of these genes have been associated with risk for nicotine dependence particularly during adulthood (Ducci et al. 2011; Wang et al. 2009).

The significant unique environmental factors shared between cigarette pack-years and subcortical regions contributed to the significant phenotypic correlations in the left nucleus accumbens and left pallidum. Previous structural MRI studies have identified significant negative phenotypic correlations between ventral striatum/nucleus accumbens in casecontrol studies (Brody et al. 2004) and in community-based samples (Das et al. 2012). Further, these ROIs have been previously identified to be important in pathways involved in the processing of the effects of nicotine administration in the presence of nicotine-related environmental stimuli (Smith et al. 2011; David et al. 2005). These results emphasize the 
importance of the role of environmental cues such as daily stressors or exposure to social situations within specific networks of smoking-related behaviors.

\section{Conclusions and Limitations}

Results from the bivariate analyses between cigarette pack-years and brain morphometry provide a deeper characterization into the etiology of smoking-related behaviors. Cortical and subcortical structures were identified that have previously been reported to play a role in specific aspects of networks of smoking-related behaviors, particularly craving control and reward/pleasure. This exploratory study demonstrated widespread, shared genetic and environmental influences on phenotypic correlations between brain structure and cigarette pack-years. These results are expected to guide future genetic association studies in neuroimaging and smoking as well as future models testing the role of specific environmental risk factors in brain circuits related to smoking-related behaviors. Future tests of these relationships in the presence of additional covariates will also help to guide understanding of etiology of nicotine dependence since no adjustments were made for the effects of covariates such as comorbid drug or alcohol use or cardiovascular disease nor were there any exclusions for participants with psychiatric history, psychotropic medication use, active combat exposure, head trauma, or hearing/speech impairment. Further, these results do not imply any direction of causation between cigarette pack-years and brain structure. The power to detect significant differences in models testing direction of causation is modest and requires additional longitudinal data to resolve.

These results should be evaluated in light of the following limitations. First, this is a relatively homogeneous, middle age, all-male sample. Therefore, associations identified in this study may not be generalized to other populations or for earlier periods of development (Jernigan et al. 2001; Giedd et al. 1999; Sowell et al. 2004; Jernigan and Gamst 2005).

However, few studies have been able to assess this relationship at the beginning of middle age and later through aging. A prior study reported current smoking to be a significant predictor of lower total cerebral brain volume in men but not women (Seshadri et al. 2004). Subsequently, these results provide necessary baseline information to understand changes in brain structure specific to smoking-related diseases and aging.

Second, these results may not generalize directly to the etiology of nicotine dependence since cigarette pack-years may only reflect average lifetime cigarette use. Further, the magnitude of the contribution of shared environmental influences for pack-years was moderate. The contribution of shared environmental effects was also moderate for the constituent measures of pack-years (number of cigarettes smoked and number of years smoked). The presence of significant shared environmental influence for pack-years is in contrast to many studies of nicotine dependence in adults for which shared environmental influences were not significant. It is likely that some of the variance due to shared environmental influences may result from the use of a 100 or greater cigarette item to identify smokers. Consequently, additional study with validated measures of nicotine dependence such as the Fagerström Test for Nicotine Dependence (Fagerstrom and Schneider 1989) is suggested. Nevertheless, average lifetime cigarette use is expected to contribute to anatomical and chemical changes in the brain (Franklin et al. 2014). Further, 
the phenotypic associations reported here are similar to others using cigarette pack-years in community-based samples of older adults (Chen et al. 2006; Das et al. 2012). Therefore, in the absence of measures of nicotine dependence, the use of cigarette pack-years holds promise for understanding the biological pathways underlying smoking-related behaviors.

Third, our power to detect additive genetic effects and genetic correlations was limited. Neither genetic or environmental covariances nor any phenotypic correlations remained significant after correction for multiple testing. Nevertheless, the identification of genes that are both associated with nicotine dependence and found gene expression studies using human brains for these specific regions represents some validation. Similarly, the detection of significant environmental covariances in regions related to pleasure-related features of nicotine dependence also suggests the validity of the results. In conclusion, these results provide important preliminary evidence for specific biological pathways of brain structure to better understand the etiology of smoking-related behaviors.

\section{References}

Agaku IT, King BA, Dube SR, Centers for Disease C, Prevention. Current cigarette smoking among adults - United States, 2005-2012. MMWR Morbidity and mortality weekly report. 2014; 63(2):2934. [PubMed: 24430098]

Centers for Disease C, Prevention. Quitting smoking among adults--United States, 2001-2010. MMWR Morbidity and mortality weekly report. 2011; 60(44):1513-1519. [PubMed: 22071589]

Chen WJ, Edwards RB, Romero RD, Parnell SE, Monk RJ. Long-term nicotine exposure reduces Purkinje cell number in the adult rat cerebellar vermis. Neurotoxicol Teratol. 2003; 25(3):329-334. [PubMed: 12757829]

Trauth JA, McCook EC, Seidler FJ, Slotkin TA. Modeling adolescent nicotine exposure: effects on cholinergic systems in rat brain regions. Brain Res. 2000; 873(1):18-25. [PubMed: 10915806]

Trauth JA, Seidler FJ, McCook EC, Slotkin TA. Adolescent nicotine exposure causes persistent upregulation of nicotinic cholinergic receptors in rat brain regions. Brain Res. 1999; 851(1-2):9-19. [PubMed: 10642823]

Xu Z, Seidler FJ, Ali SF, Slikker W Jr. Slotkin TA. Fetal and adolescent nicotine administration: effects on CNS serotonergic systems. Brain Res. 2001; 914(1-2):166-178. [PubMed: 11578609]

Brody AL, Mandelkern MA, Jarvik ME, Lee GS, Smith EC, Huang JC, Bota RG, Bartzokis G, London ED. Differences between smokers and nonsmokers in regional gray matter volumes and densities. Biol Psychiatry. 2004; 55(1):77-84. [PubMed: 14706428]

Gallinat J, Meisenzahl E, Jacobsen LK, Kalus P, Bierbrauer J, Kienast T, Witthaus H, Leopold K, Seifert F, Schubert F, Staedtgen M. Smoking and structural brain deficits: a volumetric MR investigation. Eur J Neurosci. 2006; 24(6):1744-1750. [PubMed: 17004938]

Goldstein RZ, Volkow ND. Drug addiction and its underlying neurobiological basis: neuroimaging evidence for the involvement of the frontal cortex. Am J Psychiatry. 2002; 159(10):1642-1652. [PubMed: 12359667]

Rose JE, Behm FM, Salley AN, Bates JE, Coleman RE, Hawk TC, Turkington TG. Regional brain activity correlates of nicotine dependence. Neuropsychopharmacology. 2007; 32(12):2441-2452. [PubMed: 17356570]

Menossi HS, Goudriaan AE, de Azevedo-Marques Perico C, Nicastri S, de Andrade AG, D'Elia G, Li CS, Castaldelli-Maia JM. Neural Bases of Pharmacological Treatment of Nicotine Dependence Insights from Functional Brain Imaging: A Systematic Review. CNS drugs. 2013

Agrawal A, Knopik VS, Pergadia ML, Waldron M, Bucholz KK, Martin NG, Heath AC, Madden PA. Correlates of cigarette smoking during pregnancy and its genetic and environmental overlap with nicotine dependence. Nicotine Tob Res. 2008; 10(4):567-578. [PubMed: 18418779]

Behav Genet. Author manuscript; available in PMC 2016 March 01. 
Pergadia ML, Heath AC, Martin NG, Madden PA. Genetic analyses of DSM-IV nicotine withdrawal in adult twins. Psychol Med. 2006; 36(7):963-972. [PubMed: 16749946]

Li MD, Cheng R, Ma JZ, Swan GE. A meta-analysis of estimated genetic and environmental effects on smoking behavior in male and female adult twins. Addiction. 2003; 98(1):23-31. [PubMed: 12492752]

Kremen WS, Prom-Wormley E, Panizzon MS, Eyler LT, Fischl B, Neale MC, Franz CE, Lyons MJ, Pacheco J, Perry ME, Stevens A, Schmitt JE, Grant MD, Seidman LJ, Thermenos HW, Tsuang MT, Eisen SA, Dale AM, Fennema-Notestine C. Genetic and environmental influences on the size of specific brain regions in midlife: the VETSA MRI study. NeuroImage. 2010; 49(2):1213-1223. [PubMed: 19786105]

Peper JS, Brouwer RM, Boomsma DI, Kahn RS, Hulshoff Pol HE. Genetic influences on human brain structure: a review of brain imaging studies in twins. Hum Brain Mapp. 2007; 28(6):464-473. [PubMed: 17415783]

Schmitt JE, Eyler LT, Giedd JN, Kremen WS, Kendler KS, Neale MC. Review of twin and family studies on neuroanatomic phenotypes and typical neurodevelopment. Twin Res Hum Genet. 2007; 10(5):683-694. [PubMed: 17903108]

Blokland GA, de Zubicaray GI, McMahon KL, Wright MJ. Genetic and environmental influences on neuroimaging phenotypes: a meta-analytical perspective on twin imaging studies. Twin research and human genetics : the official journal of the International Society for Twin Studies. 2012; 15(3):351-371. [PubMed: 22856370]

Baare WF, Hulshoff Pol HE, Boomsma DI, Posthuma D, de Geus EJ, Schnack HG, van Haren NE, van Oel CJ, Kahn RS. Quantitative genetic modeling of variation in human brain morphology. Cerebral cortex. 2001; 11(9):816-824. [PubMed: 11532887]

Geschwind DH, Miller BL, DeCarli C, Carmelli D. Heritability of lobar brain volumes in twins supports genetic models of cerebral laterality and handedness. Proceedings of the National Academy of Sciences of the United States of America. 2002; 99(5):3176-3181. [PubMed: 11867730]

Glahn DC, Thompson PM, Blangero J. Neuroimaging endophenotypes: strategies for finding genes influencing brain structure and function. Hum Brain Mapp. 2007; 28(6):488-501. [PubMed: 17440953]

Thompson PM, Cannon TD, Narr KL, van Erp T, Poutanen VP, Huttunen M, Lonnqvist J, Standertskjold-Nordenstam CG, Kaprio J, Khaledy M, Dail R, Zoumalan CI, Toga AW. Genetic influences on brain structure. Nature neuroscience. 2001; 4(12):1253-1258.

Kremen WS, Panizzon MS, Neale MC, Fennema-Notestine C, Prom-Wormley E, Eyler LT, Stevens A, Franz CE, Lyons MJ, Grant MD, Jak AJ, Jernigan TL, Xian H, Fischl B, Thermenos HW, Seidman LJ, Tsuang MT, Dale AM. Heritability of brain ventricle volume: converging evidence from inconsistent results. Neurobiology of aging. 2012; 33(1):1-8. [PubMed: 20363053]

Chen X, Wen W, Anstey KJ, Sachdev PS. Effects of cerebrovascular risk factors on gray matter volume in adults aged 60-64 years: a voxel-based morphometric study. Psychiatry Res. 2006; 147(2-3):105-114. [PubMed: 16962291]

Longstreth WT Jr. Arnold AM, Manolio TA, Burke GL, Bryan N, Jungreis CA, O'Leary D, Enright PL, Fried L. Clinical correlates of ventricular and sulcal size on cranial magnetic resonance imaging of 3,301 elderly people. The Cardiovascular Health Study. Collaborative Research Group. Neuroepidemiology. 2000; 19(1):30-42. [PubMed: 10654286]

Seshadri S, Wolf PA, Beiser A, Elias MF, Au R, Kase CS, D'Agostino RB, DeCarli C. Stroke risk profile, brain volume, and cognitive function: the Framingham Offspring Study. Neurology. 2004; 63(9):1591-1599. [PubMed: 15534241]

Pakkenberg B, Gundersen H. Neocortical neuron number in humans: Effect of sex and age. Jornal of Comparitive Neurology. 1997; 384:312-320.

Im K, Lee JM, Lyttelton O, Kim SH, Evans AC, Kim SI. Brain size and cortical structure in the adult human brain. Cereb Cortex. 2008; 18(9):2181-2191. [PubMed: 18234686]

Panizzon MS, Fennema-Notestine C, Eyler LT, Jernigan TL, Prom-Wormley E, Neale M, Jacobson K, Lyons MJ, Grant MD, Franz CE, Xian H, Tsuang M, Fischl B, Seidman L, Dale A, Kremen WS. Distinct Genetic Influences on Cortical Surface Area and Cortical Thickness. Cereb Cortex. 2009 
Kremen WS, Franz CE, Lyons MJ. VETSA: the Vietnam Era Twin Study of Aging. Twin research and human genetics : the official journal of the International Society for Twin Studies. 2013; 16(1): 399-402. [PubMed: 23110957]

Kremen WS, Franz CE, Lyons MJ. VETSA: the Vietnam Era Twin Study of Aging - ADDENDUM. Twin research and human genetics : the official journal of the International Society for Twin Studies. 2013; 16(1):403. [PubMed: 23394194]

Kremen WS, Thompson-Brenner H, Leung YM, Grant MD, Franz CE, Eisen SA, Jacobson KC, Boake C, Lyons MJ. Genes, environment, and time: the Vietnam Era Twin Study of Aging (VETSA). Twin research and human genetics : the official journal of the International Society for Twin Studies. 2006; 9(6):1009-1022. [PubMed: 17254445]

Goldberg J, Curran B, Vitek ME, Henderson WG, Boyko EJ. The Vietnam Era Twin Registry. Twin Res. 2002; 5(5):476-481. [PubMed: 12537880]

Eisen SA, True WR, Goldberg J, Henderson W, Robinette CD. The Vietnam Era Twin (VET) Registry: Method of construction. Acta Geneticae Medicae et Gemellologiae. 1987; 36:61-66. [PubMed: 3673478]

Henderson WG, Eisen SE, Goldberg J, True WR, Barnes JE, Vitek M. The Vietnam Era Twin Registry: A resource for medical research. Public Health Reports. 1990; 105:368-373. [PubMed: 2116638]

Eisen S, Neuman R, Goldberg J, Rice J, True W. Determining zygosity in the Vietnam Era Twin Registry: an approach using questionnaires. Clinical genetics. 1989; 35(6):423-432. [PubMed: 2736790]

Nichols RC, Bilbro WC Jr. The diagnosis of twin zygosity. Acta genetica et statistica medica. 1966; 16(3):265-275. [PubMed: 4959152]

Peeters H, Van Gestel S, Vlietinck R, Derom C, Derom R. Validation of a telephone zygosity questionnaire in twins of known zygosity. Behavior genetics. 1998; 28(3):159-163. [PubMed: 9670591]

Xian H, Scherrer JF, Eisen SA, Lyons MJ, Tsuang M, True WR, Bucholz KK. Nicotine dependence subtypes: association with smoking history, diagnostic criteria and psychiatric disorders in 5440 regular smokers from the Vietnam Era Twin Registry. Addict Behav. 2007; 32(1):137-147. [PubMed: 16647217]

Fischl B, Salat DH, Busa E, Albert M, Dieterich M, Haselgrove C, van der Kouwe A, Killiany R, Kennedy D, Klaveness S, Montillo A, Makris N, Rosen B, Dale AM. Whole brain segmentation: Automated labeling of neuroanatomical structures in the human brain. Neuron. 2002; 33:341-355. [PubMed: 11832223]

Fischl B, Salat DH, van der Kouwe AJ, Makris N, Segonne F, Quinn BT, Dale AM. Sequenceindependent segmentation of magnetic resonance images. Neuroimage. 2004; 231(Suppl):S69S84. [PubMed: 15501102]

Fischl B, Salat DH, Busa E, Albert M, Dieterich M, Haselgrove C, van der Kouwe A, Killiany R, Kennedy D, Klaveness S, Montillo A, Makris N, Rosen B, Dale AM. Whole brain segmentation: automated labeling of neuroanatomical structures in the human brain. Neuron. 2002; 33(3):341355. [PubMed: 11832223]

Fischl B, Salat DH, van der Kouwe AJ, Makris N, Segonne F, Quinn BT, Dale AM. Sequenceindependent segmentation of magnetic resonance images. NeuroImage. 2004; 231(Suppl):S69-84. [PubMed: 15501102]

Dale AM, Fischl B, Sereno MI. Cortical surface-based analysis. I. Segmentation and surface reconstruction. NeuroImage. 1999; 9(2):179-194. [PubMed: 9931268]

Fischl B, Dale AM. Measuring the thickness of the human cerebral cortex from magnetic resonance images. Proceedings of the National Academy of Sciences of the United States of America. 2000; 97(20):11050-11055. [PubMed: 10984517]

Fischl B, Sereno MI, Dale AM. Cortical surface-based analysis. II: Inflation, flattening, and a surfacebased coordinate system. NeuroImage. 1999; 9(2):195-207. [PubMed: 9931269]

Walhovd KB, Fjell AM, Reinvang I, Lundervold A, Fischl B, Salat D, Quinn BT, Makris N, Dale AM. Cortical volume and speed-of-processing are complementary in prediction of performance intelligence. Neuropsychologia. 2005; 43(5):704-713. [PubMed: 15721183] 
Fischl B, van der Kouwe A, Destrieux C, Halgren E, Segonne F, Salat DH, Busa E, Seidman LJ, Goldstein J, Kennedy D, Caviness V, Makris N, Rosen B, Dale AM. Automatically parcellating the human cerebral cortex. Cerebral Cortex. 2004; 14:11-22. [PubMed: 14654453]

Desikan RS, Segonne F, Fischl B, Quinn BT, Dickerson BC, Blacker D, Buckner RL, Dale AM, Maguire RP, Hyman BT, Albert MS, Killiany RJ. An automated labeling system for subdividing the human cerebral cortex on MRI scans into gyral based regions of interest. Neuroimage. 2006; 31:968-980. [PubMed: 16530430]

Eyler LT, Prom-Wormley E, Panizzon MS, Kaup AR, Fennema-Notestine C, Neale MC, Jernigan TL, Fischl B, Franz CE, Lyons MJ, Grant M, Stevens A, Pacheco J, Perry ME, Schmitt JE, Seidman LJ, Thermenos HW, Tsuang MT, Chen CH, Thompson WK, Jak A, Dale AM, Kremen WS. Genetic and environmental contributions to regional cortical surface area in humans: a magnetic resonance imaging twin study. Cerebral cortex. 2011; 21(10):2313-2321. [PubMed: 21378112]

Eyler LT, Chen CH, Panizzon MS, Fennema-Notestine C, Neale MC, Jak A, Jernigan TL, Fischl B, Franz CE, Lyons MJ, Grant M, Prom-Wormley E, Seidman LJ, Tsuang MT, Fiecas MJ, Dale AM, Kremen WS. A comparison of heritability maps of cortical surface area and thickness and the influence of adjustment for whole brain measures: a magnetic resonance imaging twin study. Twin research and human genetics : the official journal of the International Society for Twin Studies. 2012; 15(3):304-314. [PubMed: 22856366]

Neale, MC.; Boker, SM.; Xie, G.; Maes, HH. Mx: Statistical Modeling. 6th Edition ed.. Department of Psychiatry; Richmond, VA: 2006.

Das D, Cherbuin N, Anstey KJ, Sachdev PS, Easteal S. Lifetime cigarette smoking is associated with striatal volume measures. Addiction biology. 2012; 17(4):817-825. [PubMed: 21392170]

May A, Hajak G, Ganssbauer S, Steffens T, Langguth B, Kleinjung T, Eichhammer P. Structural brain alterations following 5 days of intervention: dynamic aspects of neuroplasticity. Cerebral cortex. 2007; 17(1):205-210. [PubMed: 16481564]

Ferrea S, Winterer G. Neuroprotective and neurotoxic effects of nicotine. Pharmacopsychiatry. 2009; 42(6):255-265. [PubMed: 19924585]

Im K, Lee JM, Lyttelton O, Kim SH, Evans AC, Kim SI. Brain size and cortical structure in the adult human brain. Cerebral cortex. 2008; 18(9):2181-2191. [PubMed: 18234686]

Pakkenberg B, Gundersen HJ. Neocortical neuron number in humans: effect of sex and age. The Journal of comparative neurology. 1997; 384(2):312-320. [PubMed: 9215725]

Sanabria-Diaz G, Melie-Garcia L, Iturria-Medina Y, Aleman-Gomez Y, Hernandez-Gonzalez G, Valdes-Urrutia L, Galan L, Valdes-Sosa P. Surface area and cortical thickness descriptors reveal different attributes of the structural human brain networks. NeuroImage. 2010; 50(4):1497-1510. [PubMed: 20083210]

O'Doherty J, Rolls ET, Francis S, Bowtell R, McGlone F, Kobal G, Renner B, Ahne G. Sensoryspecific satiety-related olfactory activation of the human orbitofrontal cortex. Neuroreport. 2000; 11(2):399-403. [PubMed: 10674494]

Breiter HC, Rosen BR. Functional magnetic resonance imaging of brain reward circuitry in the human. Annals of the New York Academy of Sciences. 1999; 877:523-547. [PubMed: 10415669]

Koob GF, Volkow ND. Neurocircuitry of addiction. Neuropsychopharmacology : official publication of the American College of Neuropsychopharmacology. 2010; 35(1):217-238. [PubMed: 19710631]

Volkow ND, Fowler JS, Wang GJ. Positron emission tomography and single-photon emission computed tomography in substance abuse research. Seminars in nuclear medicine. 2003; 33(2): 114-128. [PubMed: 12756644]

Ducci F, Kaakinen M, Pouta A, Hartikainen AL, Veijola J, Isohanni M, Charoen P, Coin L, Hoggart C, Ekelund J, Peltonen L, Freimer N, Elliott P, Schumann G, Jarvelin MR. TTC12-ANKK1-DRD2 and CHRNA5-CHRNA3-CHRNB4 influence different pathways leading to smoking behavior from adolescence to mid-adulthood. Biological psychiatry. 2011; 69(7):650-660. [PubMed: 21168125]

Wang JC, Cruchaga C, Saccone NL, Bertelsen S, Liu P, Budde JP, Duan W, Fox L, Grucza RA, Kern J, Mayo K, Reyes O, Rice J, Saccone SF, Spiegel N, Steinbach JH, Stitzel JA, Anderson MW, You M, Stevens VL, Bierut LJ, Goate AM, collaborators C, collaborators G. Risk for nicotine 
dependence and lung cancer is conferred by mRNA expression levels and amino acid change in CHRNA5. Human molecular genetics. 2009; 18(16):3125-3135. [PubMed: 19443489]

Brody AL, Olmstead RE, London ED, Farahi J, Meyer JH, Grossman P, Lee GS, Huang J, Hahn EL, Mandelkern MA. Smoking-induced ventral striatum dopamine release. Am J Psychiatry. 2004; 161(7):1211-1218. [PubMed: 15229053]

Smith KS, Berridge KC, Aldridge JW. Disentangling pleasure from incentive salience and learning signals in brain reward circuitry. Proceedings of the National Academy of Sciences of the United States of America. 2011; 108(27):E255-264. [PubMed: 21670308]

David SP, Munafo MR, Johansen-Berg H, Smith SM, Rogers RD, Matthews PM, Walton RT. Ventral striatum/nucleus accumbens activation to smoking-related pictorial cues in smokers and nonsmokers: a functional magnetic resonance imaging study. Biological psychiatry. 2005; 58(6): 488-494. [PubMed: 16023086]

Jernigan TL, Archibald SL, Fennema-Notestine C, Gamst AC, Stout JC, Bonner J, Hesselink JR. Effects of age on tissues and regions of the cerebrum and cerebellum. Neurobiology of Aging. 2001; 22:581-594. [PubMed: 11445259]

Giedd JN, Blumenthal J, Jeffries NO, Castellanos FX, Liu H, Zijdenbos A, Paus T, Evans AC, Rapoport JL. Brain development during childhood and adolescence: a longitudinal MRI study. Nat Neurosci. 1999; 2(10):861-863. [PubMed: 10491603]

Sowell ER, Thompson PM, Leonard CM, Welcome SE, Kan E, Toga AW. Longitudinal mapping of cortical thickness and brain growth in normal children. J Neurosci. 2004; 24:8223-8231. [PubMed: 15385605]

Jernigan TL, Gamst AC. Changes in volume with age--consistency and interpretation of observed effects. Neurobiol Aging. 2005; 26(9):1271-1274. [PubMed: 16006011]

Fagerstrom KO, Schneider NG. Measuring nicotine dependence: a review of the Fagerstrom Tolerance Questionnaire. Journal of behavioral medicine. 1989; 12(2):159-182. [PubMed: 2668531]

Franklin TR, Wetherill RR, Jagannathan K, Johnson B, Mumma J, Hager N, Rao H, Childress AR. The effects of chronic cigarette smoking on gray matter volume: influence of sex. PloS one. 2014; 9(8):e104102. [PubMed: 25090480] 


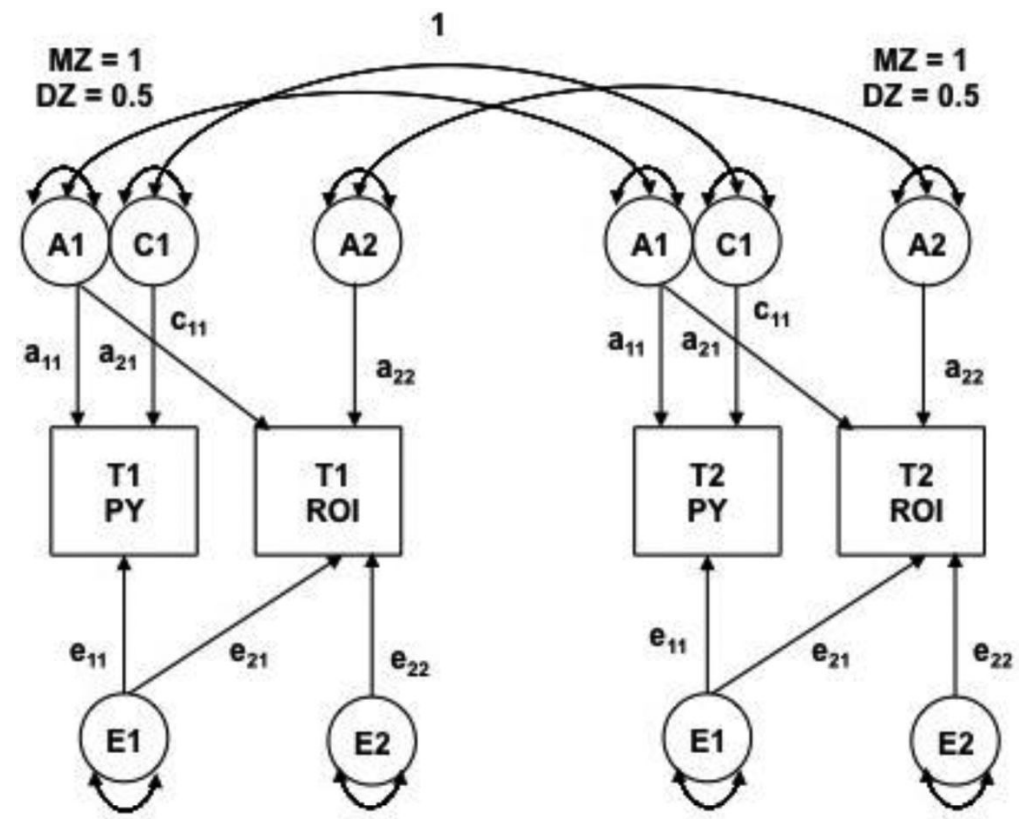

Figure 1.

Final Bivariate Model Used to Test Relationships Across All Regions of Interest (ROI) of Brain Structure and Cigarette pack-years.

$\mathrm{A} 1, \mathrm{C} 1$ and $\mathrm{E} 1$ refer to the additive genetic, shared environmental and unique environmental contributing to the total variance of cigarette pack-years (PY). A2 and E2 refer to the additive genetic and unique environmental influences contributing to a specific region of interest (ROI). Paths $\mathrm{a}_{21}$ and $\mathrm{e}_{21}$ reflect those used to estimate the genetic and environmental influences shared between cigarette pack-years and brain structure size. 

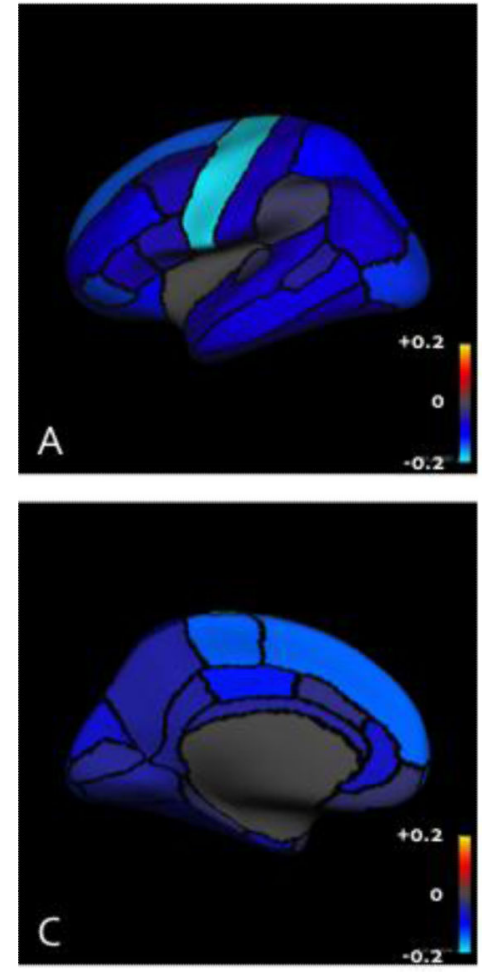
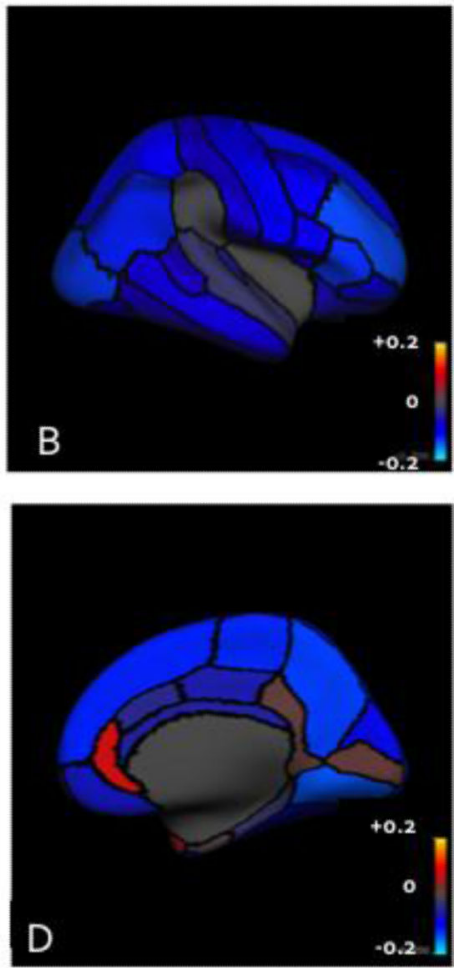

Figure 2.

Phenotypic Correlations between Cigarette pack-years and All Volume Measures of Cortical Regions for (A) Left Lateral, (B) Right Lateral, (C) Left Medial, and (D) Right Medial Views 


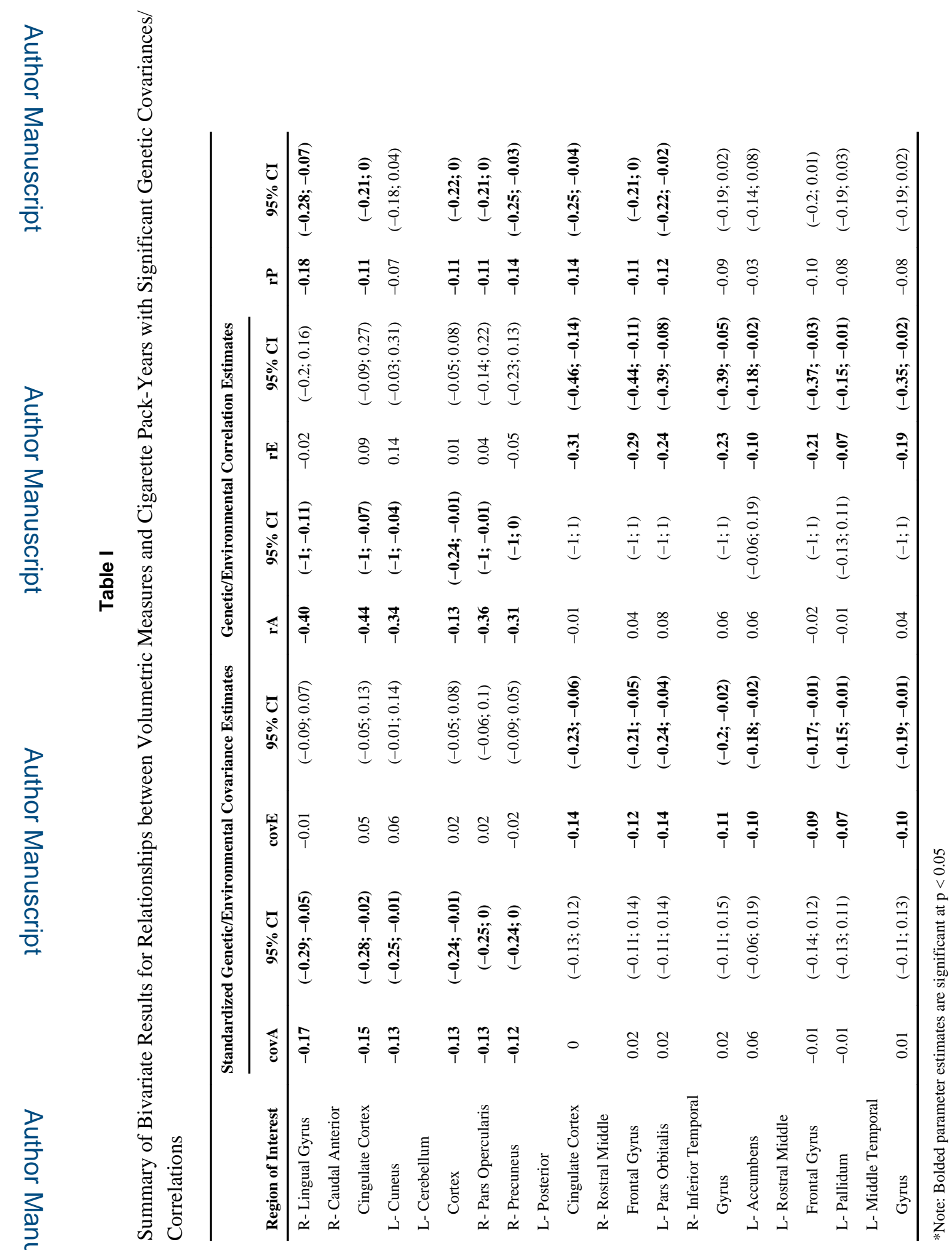

Behav Genet. Author manuscript; available in PMC 2016 March 01. 


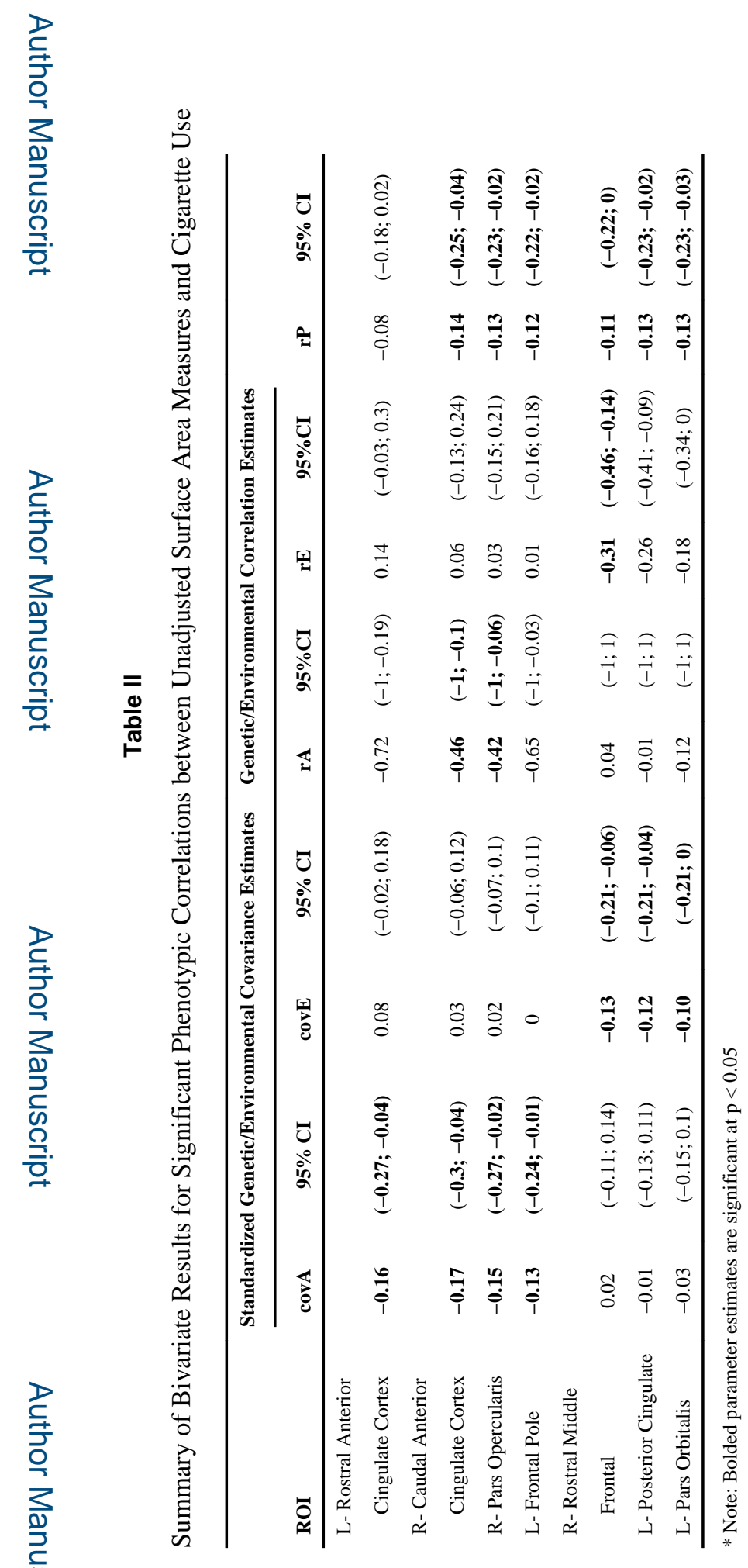

Behav Genet. Author manuscript; available in PMC 2016 March 01. 


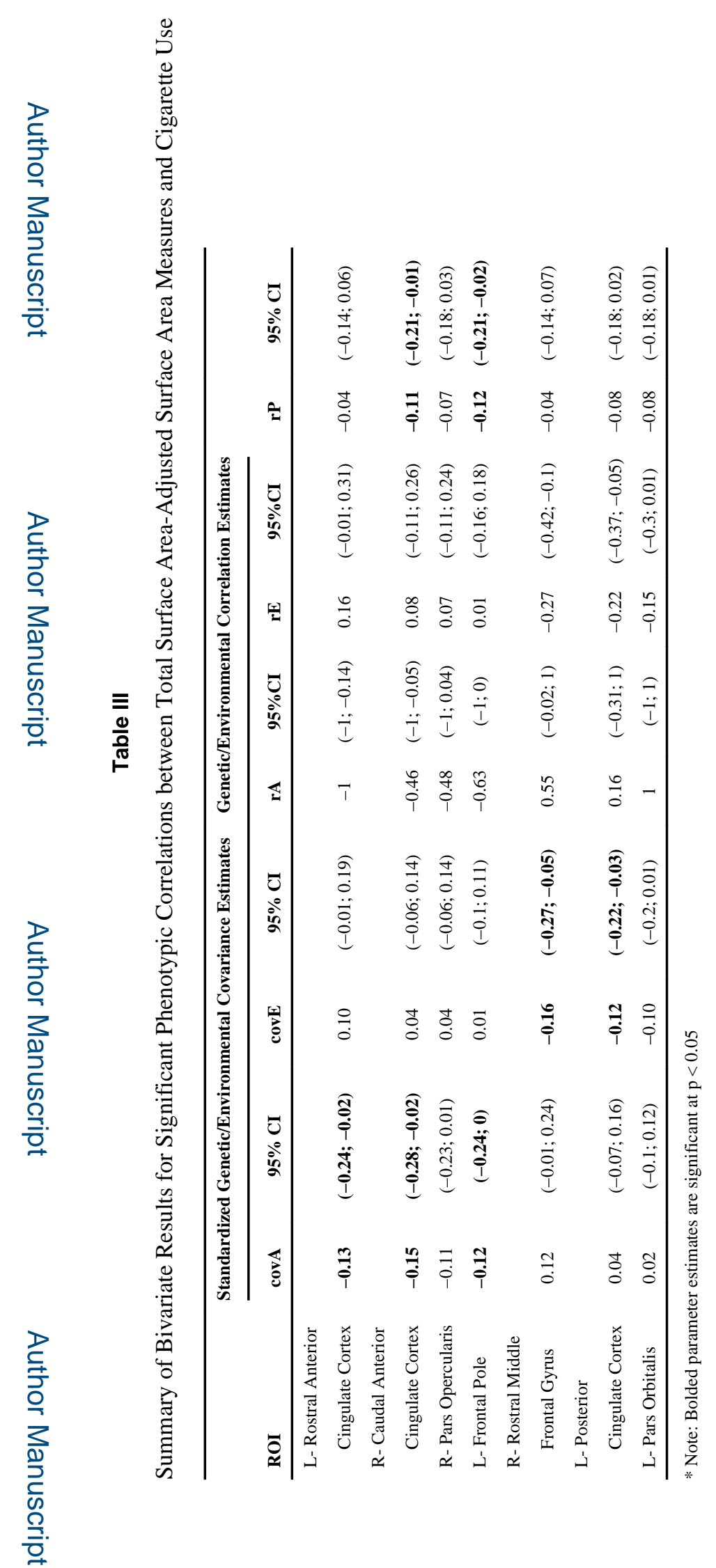

Behav Genet. Author manuscript; available in PMC 2016 March 01. 